\title{
Adsorption of benzene, cyclohexane and hexane on ordered mesoporous carbon
}

\author{
Gang Wang ${ }^{1}$, Baojuan Dou ${ }^{1}$, Zhongshen Zhang $^{1}$, Junhui Wang ${ }^{1}$, \\ Haier Liu ${ }^{2}$, Zhengping $\mathrm{Hao}^{1, *}$ \\ 1. Research Center for Eco-Environmental Sciences, Chinese Academy of Sciences, Beijing 100085, China. E-mail: wgbift@126.com \\ 2. School of Materials Science and Engineering, University of Science and Technology Beijing, Beijing 100083, China
}

\section{A R T I C L E I N F O}

Article history:

Received 15 May 2014

Revised 6 October 2014

Accepted 10 October 2014

Available online 23 February 2015

Keywords:

Volatile organic compounds

Adsorption

Ordered mesoporous carbon

Isosteric heat of adsorption

Knudsen diffusion

\begin{abstract}
A B S T R A C T
Ordered mesoporous carbon (OMC) with high specific surface area and large pore volume was synthesized and tested for use as an adsorbent for volatile organic compound (VOC) disposal. Benzene, cyclohexane and hexane were selected as typical adsorbates due to their different molecular sizes and extensive utilization in industrial processes. In spite of their structural differences, high adsorption amounts were achieved for all three adsorbates, as the pore size of OMC is large enough for the access of these VOCs. In addition, the unusual bimodal-like pore size distribution gives the adsorbates a higher diffusion rate compared with conventional adsorbents such as activated carbon and carbon molecular sieve. Kinetic analysis suggests that the adsorption barriers mainly originated from the difficulty of VOC vapor molecules entering the pore channels of adsorbents. Therefore, its superior adsorption ability toward VOCs, together with a high diffusion rate, makes the ordered mesoporous carbon a promising potential adsorbent for VOC disposal.

(c) 2015 The Research Center for Eco-Environmental Sciences, Chinese Academy of Sciences.
\end{abstract} Published by Elsevier B.V.

\section{Introduction}

Volatile organic compounds (VOCs) are a class of air pollutants in industrial processes and daily human consumption (Lin et al., 2011; Parmar and Rao, 2009; He et al., 2012; Hernandez et al., 2003; Ghoshal and Manjare, 2002; Reguer et al., 2011; Gonzalez-Miquel et al., 2013). Because of their high vapor pressure and low boiling point, they are prone to be emitted into the atmosphere, causing great environmental problems because of their intrinsically hazardous properties. Not only they are the main precursors of photochemical reaction in the atmosphere, inducing ozone destruction and photochemical smog, but they are also toxic toward human health, and may cause pathogenic, mutagenic and even fatal diseases (Wang et al., 2007; Parmar and Rao, 2009;
He et al., 2012; Hernandez et al., 2003). Unfortunately, with the continuous development of industrialization in recent years, the emissions of VOCs have gradually increased to a new high level (Ghoshal and Manjare, 2002; Wu et al., 2011). In order to reduce the harmful effect of VOCs on the environment and humans, stringent regulations have already been enforced to limit further VOC emission. Meanwhile, the abatement technologies for VOCs have aroused great attention and they are considered a major component in the elimination of pollution.

Various kinds of methods, such as catalytic oxidation, adsorption, absorption, photocatalytic processes, and biological methods are employed for the abatement of VOCs (Wang et al., 2007; Parmar and Rao, 2009; He et al., 2012; Hernandez et al., 2003; Ghoshal and Manjare, 2002; Reguer et al., 2011;

\footnotetext{
* Corresponding author. E-mail: zpinghao@rcees.ac.cn (Zhengping Hao).
} 
Gonzalez-Miquel et al., 2013). Among them, adsorption technology seems to be the preferred choice due to its great advantages of convenience and high efficiency (Hernandez et al., 2003; Ghoshal and Manjare, 2002; Reguer et al., 2011). In addition, the adsorption process is an important intermediate step when considering the recovery of valuable VOCs (Ghoshal and Manjare, 2002; Ramirez et al., 2005). It is generally accepted that for adsorption technology, a proper adsorbent is important for the efficient removal of VOCs. Until now, activated carbon has been used as the most popular adsorbent due to its low cost and relatively good adsorption properties (Ramirez et al., 2005; Lillo-Rodenas et al., 2006; de Souza et al., 2012). However, some weaknesses have limited its further application. Activated carbon is a typical microporous adsorbent, with most pores in the micropore range $(<2 \mathrm{~nm})$, which may slow the transport velocity of VOC molecules. In addition, the irregularly shaped pores in activated carbon increase the diffusion resistance of adsorbate molecules during the adsorption process and a long time is needed to reach adsorption equilibrium (Nevskaia et al., 2004; Ji et al., 2010; Britt et al., 2008). Thus a new adsorbent with high specific surface area, large pore volume and relative larger pore size is urgently needed.

Ordered mesoporous carbon (OMC) is a kind of mesoporous material possessing high specific surface area, large pore volume and tunable pore size, which can be used as a catalyst support and adsorbent as well as in electric capacitors (Wang et al., 2013; Hartmann et al., 2005; Tanaka et al., 2013). Generally, OMC can be synthesized using low-molecular-weight resol as carbon source, silica as an additive and triblock copolymer Pluronic F127 as a structure-directing agent via the evaporation-induced self-assembly (EISA) method (Ma et al., 2013; Li and Zhao, 2013). Benefiting from its relatively large surface area and pore volume, OMC shows great potential advantages as an adsorbent in environmental remediation processes. Hartmann et al. (2005) investigated the adsorption properties of Vitamin E on mesoporous carbon molecular sieves, and the large adsorption amount indicated the superior adsorption properties of mesoporous carbon molecular sieves compared to microporous carbon adsorbents. In addition, they certified that the adsorption process takes place in the channels of the mesoporous carbon adsorbent, contrary to the conventional opinion that mesoporous channels only provide passage for adsorbate molecules rather than supplying efficient adsorption sites (Hartmann et al., 2005). Zhuang et al. (2009) used OMCs for the efficient disposal of wastewater containing bulky dye molecules for the first time. The results suggested that OMC can be used as an efficient adsorbent for removing bulky dye molecules from water. They proved that a mesoporous carbon with high surface area, large pore volume and bimodal pores showed the highest adsorption capacity among three selected OMCs with different pore structures. Recently, Yuan et al. (2013) adopted OMC as an adsorbent for the separation of $\mathrm{CO}_{2}$ and $\mathrm{N}_{2}$ from $\mathrm{CH}_{4}$, and the results indicated that $\mathrm{OMC}$ is a useful adsorbent, displaying both high selectivity and large adsorption capacity. These relevant studies indicate the superior adsorption properties of OMC. However, as a typical class of pollutant, the adsorption properties of VOCs on OMC have been relatively less studied, to the best of our knowledge.

In this study, OMC was synthesized via the EISA route and the adsorption properties of three typical kinds of VOCs on
OMC were studied to investigate the potential application of OMC in VOC adsorption. The selected VOCs were benzene, cyclohexane and hexane, which have different molecular structures based on six carbon atoms and are used in substantial amounts in industrial processes. The adsorption equilibrium and kinetics of the selected VOCs were studied and isosteric heats of adsorption were calculated. In addition, relationships between the adsorption properties and structures of the selected VOC molecule were discussed.

\section{Materials and methods}

\subsection{Chemicals}

Poly(propylene oxide)-b-poly(ethylene oxide)-b-poly(propylene oxide) triblock copolymer Pluronic F127 was purchased from Sigma-Aldrich Company. Ethyl silicate $\left(\mathrm{SiO}_{2}, 28.4 \%+\right)$, phenol (99.5\%+), formaldehyde solution (37.0\%-40.0\% aqueous solution), sodium hydroxide (96.0\%), hydrochloric acid (36.0\%-38.0\%), ethanol $(99.7 \%+)$, and hydrofluoric acid $(40.0 \%+)$ were purchased from Sinopharm Chemical Reagent Company. All chemicals were used as received without any purification process. Deionized water was used in all the experiments.

\subsection{Synthesis of materials}

Resol was first prepared from phenol and formaldehyde solution in a base-catalyzed process and refrigerated for the later procedure. Then the OMC was synthesized via the EISA process with some minor modifications by our group (Gao et al., 2011). Typically, $1.6 \mathrm{~g}$ F127 was dissolved in $6.0 \mathrm{~g}$ ethanol at $313 \mathrm{~K}$, then $5.0 \mathrm{~g}$ resol solution was added to form mixture A. $2.08 \mathrm{~g}$ TEOS was added into the $1.0 \mathrm{~g} \mathrm{HCl}$ solution $(0.2 \mathrm{~mol} / \mathrm{L})$ and stirred for $30 \mathrm{~min}$ at $313 \mathrm{~K}$ to form mixture $\mathrm{B}$. Then, mixture $\mathrm{B}$ was poured into A. After stirring for $30 \mathrm{~min}$, the solution was transferred into dishes. The transparent thin film was scraped from dishes after the evaporation of ethanol and placed into a tubular furnace for a further carbonization process. The film was calcined at $623 \mathrm{~K}$ for $3 \mathrm{hr}$ under nitrogen protection with a heating rate of $2 \mathrm{~K} / \mathrm{min}$ and a nitrogen flow of $50 \mathrm{~mL} / \mathrm{min}$, respectively. Then the temperature was raised to $1173 \mathrm{~K}$ with the heating rate being $1 \mathrm{~K} / \mathrm{min}$ and remained $2 \mathrm{hr}$ for further carbonization. After that, the obtained composite was stirred in HF solution for $12 \mathrm{hr}$ to remove the silica and finally synthesized OMC was obtained after drying at $378 \mathrm{~K}$ for $5 \mathrm{hr}$.

\subsection{Material characterization}

X-ray diffraction $(\mathrm{XRD})$ patterns were recorded on a PANalytical X'Pert PRO MPD using $\mathrm{Cu}-\mathrm{K} \alpha$ radiation $(\lambda=1.540598 \AA$ ). High-resolution transmission electron microscopy (HRTEM) analysis was conducted on a JEOL 2011 microscope at $200 \mathrm{kV}$. Textural properties were obtained using nitrogen sorption isotherms at liquid nitrogen temperature on a NOVA 1200 gas sorption analyzer. The BET surface area was calculated using experimental points at relative pressures of $\mathrm{P} / \mathrm{P}_{0}=0.05-0.25$. Total pore volume was obtained by the nitrogen amount adsorbed at $P / P_{0}=0.99$. Pore size distributions were calculated by analyzing the desorption branch of isotherms based on the 
Barrett-Joyner-Halenda (BJH) method. The thermogravimetric (TG) and differential thermogravimetric (DTG) analyses of samples were carried out on a Setaram Labsys-16 thermal analyzer. The heating rate was $10 \mathrm{~K} / \mathrm{min}$ from 323 to $1173 \mathrm{~K}$ under an air flow of $30 \mathrm{~mL} / \mathrm{min}$.

\subsection{Static adsorption measurements}

The adsorption properties of benzene, cyclohexane and hexane on OMC were measured on a Hiden Intelligent Gravimetric Analyzer IGA-002 (Hiden analytical company, Warrington, United Kingdom). The instrument is equipped with an electric heater that can be used to heat and blow out hot air to generate organic vapors. The OMC sample was located in a high vacuum chamber with a constant temperature with the adsorption temperature stabilized by a water bath. Before measuring, the relative pressures of the adsorption isotherms were set and recorded by computer. During the static adsorption procedure, organic vapors were controlled precisely by turbo molecular pump and allowed the adsorption to proceed following the set relative pressure values. In this work, 298, 308 and $318 \mathrm{~K}$ were selected as adsorption temperatures. The saturation vapor pressures of adsorbates were calculated following the Antoine equation (Speight, 2005):

$\log p_{0}=A-\frac{B}{T+C-273}$

where, $p_{0}$ (Torr) is the saturated vapor pressure, $T(K)$ is the temperature and $A, B$, and $C$ are the constants defined by the adsorbate; benzene (281-376 K): $A=6.90565, B=1211.033$, and $C=220.790 ; \quad$ cyclohexane: $A=6.88617, \quad B=1229.973$, and $C=224.10$; and hexane (248-365 K): $A=6.87601, B=1171.17$, and $C=224.41$. The corresponding physico-chemical properties of the three kinds of VOCs are listed in Table 1 (Speight, 2005; Webster et al., 1998; Li et al., 2009).

\section{Results and discussion}

\subsection{Characterization of OMC}

The X-ray diffraction (XRD) patterns of the synthesized OMC are shown in Fig. S1 in the Supporting Information. The weak broad diffraction peak around $43^{\circ}$ in the wide-angle XRD pattern (a) indicates the long-range disorder of OMC. The well-defined diffraction peak at $0.83^{\circ}$ in the small-angle XRD pattern (b) can be indexed as the (100) diffraction for a typical 2D hexagonal meso-structure, suggesting that the ordered mesoporous structure was formed successfully via the EISA method. The calculated cell parameter is $12.3 \mathrm{~nm}$, according to the following equation:

$a_{0}=2 d_{100} / \sqrt{3}$

where $d_{100}$ is the (100) lattice spacing and can be calculated from the equation:

$d_{100}=\lambda / 2 \sin \theta$.

In this study, the (100) lattice spacing is $10.6 \mathrm{~nm}$. Fig. S2 shows the TEM image of the synthesized OMC taken from the direction perpendicular to the pore channels. The stripe-like arrangement of pores further confirms the 2D ordered meso-structure, although the XRD diffraction peaks in the range $1-3^{\circ}$ were not as resolved as the diffraction peak at $0.83^{\circ}$.

Fig. S3 shows the TG analysis curve for OMC. The minor weight loss around $373 \mathrm{~K}$ was attributed to the loss of water and other small adsorbates. The main weight loss, approximately $100 \%$, occurs between 573 and $973 \mathrm{~K}$, suggesting that the silica component was almost completely removed by HF etching. Furthermore, the weight loss around $673 \mathrm{~K}$ is only $10 \%$ of the total weight, indicating that the synthesized OMC can be used under $673 \mathrm{~K}$ with a relatively high thermal stability.

Nitrogen adsorption/desorption isotherms and pore size distribution curve are depicted in Fig. S4. As shown in Fig. S4a, the isotherm can be divided into three parts. In the low relative pressure region $\left(P / P_{0}<0.1\right)$, small amounts of nitrogen were adsorbed onto $\mathrm{OMC}$, indicating the existence of a small amount of micropores. As the relative pressure gradually raised, the adsorbed amounts of nitrogen increased and a typical adsorption/desorption hysteresis loop appeared. According to the definition of IUPAC, the type IV adsorption/ desorption isotherm suggests the presence of mesopores (Sing, 1985). In addition, the corresponding $\mathrm{H} 1$ hysteresis loop at relative pressures between 0.5 and 0.8 suggests the

\section{Table 1 - Physical-chemical parameters of selected vapor adsorbate.}

\begin{tabular}{|c|c|c|c|c|c|c|c|}
\hline \multirow[t]{2}{*}{ Adsorbate } & \multirow[t]{2}{*}{ Structure } & \multirow[t]{2}{*}{ Relative molecular mass } & \multirow[t]{2}{*}{ Density $(\mathrm{g} / \mathrm{mL})$} & \multirow[t]{2}{*}{ Boiling point/K } & \multicolumn{3}{|c|}{$\begin{array}{c}\text { Molecular } \\
\text { dimensions }(\AA)\end{array}$} \\
\hline & & & & & $x$ & $y$ & z \\
\hline Benzene & & 78.11 & 0.879 & 353 & 6.628 & 7.337 & 3.277 \\
\hline Cyclohexane & & 84.16 & 0.779 & 353.7 & 7.168 & 6.580 & 4.982 \\
\hline Hexane & & 86.18 & 0.660 & 342 & 10.344 & 4.536 & 4.014 \\
\hline
\end{tabular}


existence of straight pore channels, in good agreement with the XRD data and the TEM image. In the high relative pressure region $\left(P / P_{0}>0.8\right)$, a plateau occurs in the isotherms and the adsorbed amounts of nitrogen stabilize at about $1200 \mathrm{~cm}^{3} / \mathrm{g}$. The calculated BET specific surface area and total pore volume are 1762 and $1.75 \mathrm{~cm}^{3} / \mathrm{g}$ respectively, while the micropore volume is $0.18 \mathrm{~cm}^{3} / \mathrm{g}$. This value shows that most of the pore volume is from the mesopores rather than micropores. The $\mathrm{BJH}$ pore size distribution curve in Fig. S4b suggests that there is a bimodal-like pore size distribution, with the most probable pore sizes being 5.0 and $1.8 \mathrm{~nm}$. The primary mesopore size corresponds to the main pore of the hexagonal channel originating from the removal of the triblock copolymer template, and the secondary mesopore comes from the etching of the silica component in the silica-carbon wall.
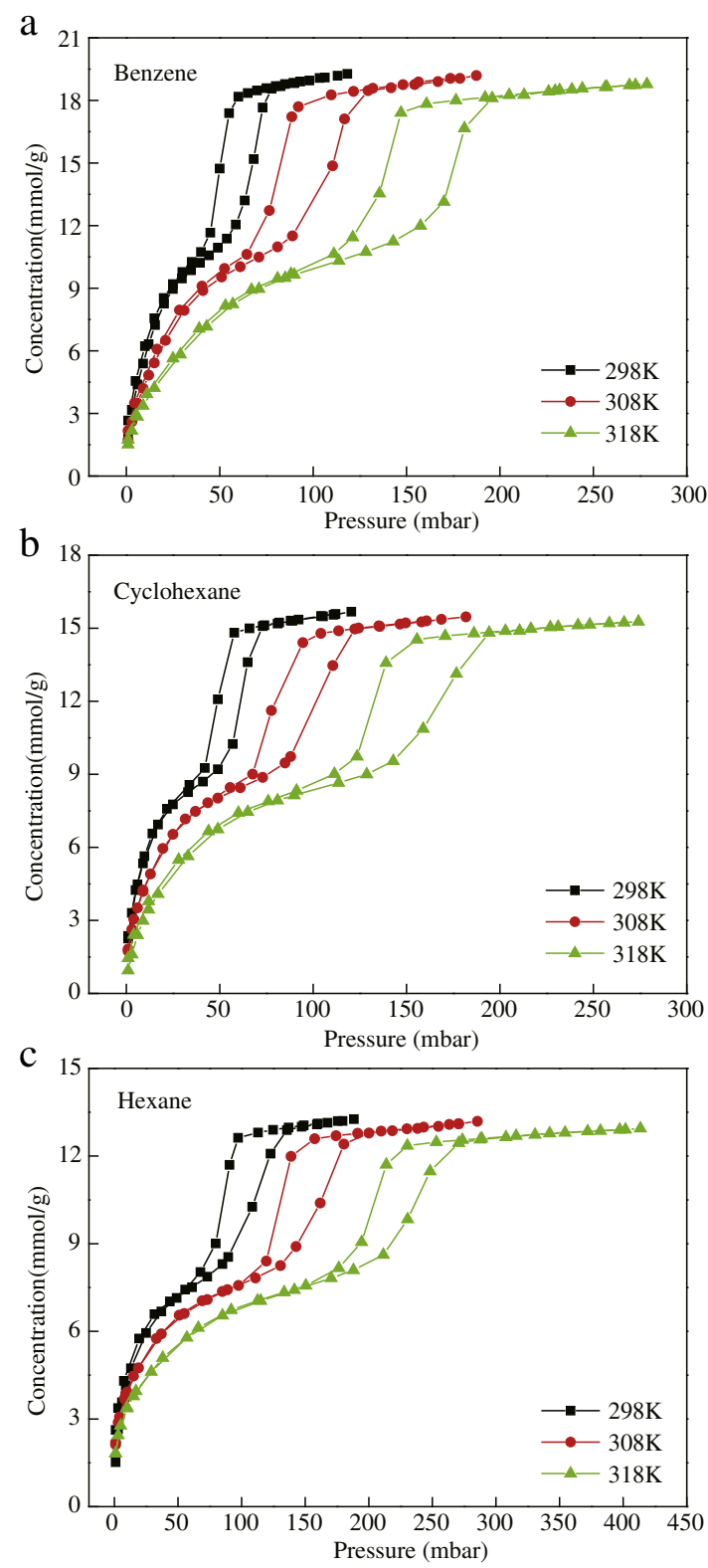

Fig. 1 - Adsorption/desorption isotherms of benzene (a), cyclohexane (b), and hexane (c) onto ordered mesoporous carbon (OMC).

\begin{tabular}{llrrr}
$\begin{array}{l}\text { Table } \\
\text { adsorbates under different temperature. }\end{array}$ & selected & vapor \\
\hline \multicolumn{2}{c}{ Adsorbate temperature $(\mathrm{K})$} & 298 & 308 & 318 \\
\hline \multirow{2}{*}{ Benzene } & Adsorption amount $(\mathrm{mmol} / \mathrm{g})$ & 17.34 & 16.86 & 16.71 \\
& Pore volume $\left(\mathrm{cm}^{3}\right)$ & 1.54 & 1.50 & 1.49 \\
Cyclohexane & Adsorption amount (mmol/g) & 14.19 & 13.92 & 13.68 \\
& Pore volume $\left(\mathrm{cm}^{3}\right)$ & 1.53 & 1.51 & 1.48 \\
Hexane & Adsorption amount $(\mathrm{mmol} / \mathrm{g})$ & 11.97 & 11.85 & 11.82 \\
& Pore volume $\left(\mathrm{cm}^{3}\right)$ & 1.56 & 1.55 & 1.54 \\
\hline
\end{tabular}

\subsection{Adsorption of benzene, cyclohexane and hexane on OMC}

Adsorption/desorption isotherms of benzene, cyclohexane and hexane onto OMC are depicted in Fig. 1. All adsorption isotherms show type IV isotherm behavior and exhibit three well-defined stages, just as in the nitrogen adsorption/ desorption isotherm. At the initial stage, a sharp increase of adsorption occurs with the growth of saturated vapor pressure, suggesting high affinity between the three kinds of adsorbates and OMC. A similar increase in adsorption in the intermediate stage indicates multi-layer adsorption of adsorbates onto OMC. In addition, the hysteresis loops further confirm the mesoporous structure of OMC. In the final stage, with relatively higher vapor pressure, the adsorption of adsorbates reaches a saturation value, implying the available pore volume of OMC is completely filled. This corresponds to the finding in previous research that under high relative vapor pressure, the adsorbed amount is related to the available pore volume (Bell et al., 2011). The maximum adsorption amounts of each adsorbate were extrapolated based on the linear part of the third stage, and the corresponding amounts are depicted in Table 2. The adsorption of benzene reached $17.34 \mathrm{mmol} / \mathrm{g}$ at $298 \mathrm{~K}$, and this value is higher than that obtained with other adsorbents (Yang et al., 2011; Yu et al., 2006; Wang et al., 2011; Fletcher et al., 2006). Furthermore, it is worthy to note that the amount adsorbed was about $7 \mathrm{mmol} / \mathrm{g}$ as the relative vapor pressure reached about $P / P_{0}=0.1$, showing a very useful property of OMC for the sorptive removal of VOCs at low concentrations (Jhung et al., 2007). For cyclohexane and hexane, the maximum adsorption amounts were 14.19 and $11.97 \mathrm{mmol} / \mathrm{g}$ respectively, lower than the corresponding benzene adsorption amount. In addition, the adsorption of each adsorbate gradually decreased with increasing temperature from 298 to $318 \mathrm{~K}$, indicating the physical nature of the adsorption of VOCs on OMC. The pore volume of OMC available for VOC adsorption was also calculated using the adsorption amounts, and the liquid density of the adsorbates is shown in Table 1. As can be seen in Table 2, the pore volumes calculated for different adsorbates are similar, indicating that OMC is useful for the adsorption of both relatively small adsorbates like benzene and relatively larger adsorbates such as hexane, whose molecules behave as a plane and elongated cylinder, respectively. This universal adsorption property for both small and large adsorbates is important in circumstances where the exhaust gases include mixtures of VOCs such as benzene and hexane. This is 
quite different from cases with some adsorbents that only selectively adsorb benzene over hexane, or where some adsorbates are excluded from a portion of the pores owing to the selective porosity of the adsorbents (Li et al., 2009; Reid and Thomas, 2001). Considering the textural properties of OMC, the universal adsorption properties may derive from the hierarchical pore size distribution of OMC. As revealed in Fig. S4, the OMC possesses a bimodal-like pore size distribution with the pore sizes of 5.0 and $1.8 \mathrm{~nm}$, both of which are larger than the three dimensional sizes of the molecules studied, and thus fully accessible for benzene, cyclohexane and hexane.

\subsection{Adsorption isotherms}

Various adsorption isotherm equations are used to fit adsorption data. Among them, the virial equation is used extensively and the corresponding formula can be written in the form (Reid and Thomas, 2001),

$\ln (n / p)=A_{0}+A_{1} n+A_{2} n^{2}+A_{3} n^{3}---$

where, $n$ is the adsorbed amount at pressure $p ; A_{0}$ is the first virial coefficient, which is related to the Henry's law constant $K_{0}$ according to the equation $K_{0}=\exp \left(A_{0}\right)$. The Henry's law constant $K_{0}$ represents the interaction between the adsorbent surfaces and the adsorbed gas molecules. The second virial parameter $\left(A_{1}\right)$ is a function of adsorbate/adsorbate interactions.

In this research, the virial equation was adopted to simulate the adsorption isotherms of benzene, cyclohexane and hexane on $\mathrm{OMC}$, and the corresponding virial parameters are listed in Table 3 . It is clear that as the temperature increases, the $A_{0}$ value is more negative, i.e. the $K_{0}$ parameter decreases, suggesting a gradually weaker adsorbate-adsorbent interaction as the temperature increases from 298 to $318 \mathrm{~K}$. This is in accordance with the exothermic characteristics of physical adsorption. Similarly, the $A_{1}$ value becomes more negative, representing a weaker adsorbate-adsorbate interaction as the temperature increases. At the same temperature, the $K_{0}$ value for the adsorbates varies in the order hexane $>$ cyclohexane $>$ benzene, reflecting the higher affinity of hexane than cyclohexane and benzene. This may be caused by the relatively higher molecular mass of hexane than the other two adsorbates, considering that adsorbates with higher molecular weight are more susceptible to adsorb on an adsorbent (Wang et al., 2012).

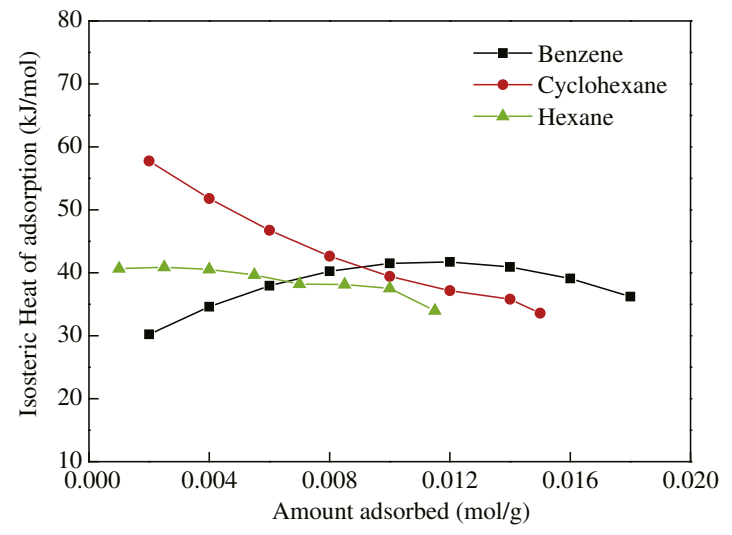

Fig. 2 - Isosteric heats of adsorption for benzene, cyclohexane and hexane.

\subsection{Isosteric heats of adsorption}

Isosteric heats of adsorption are important to evaluate the temperature change during the adsorption procedure. The value can be calculated from the isotherms measured at different temperatures using the Van't Hoff equation, which is given by the following expression,

$\ln (p)_{n}=\frac{\Delta H_{n}}{R T}-\frac{\Delta S_{n}}{R}$

where, $\Delta H_{n}(\mathrm{~kJ} / \mathrm{mol})$ is the isosteric heat of adsorption, $T(\mathrm{~K})$ is adsorption temperature, $p(\mathrm{~Pa})$ is the pressure, $\mathrm{R}$ is the gas constant, $n(\mathrm{~mol} / \mathrm{g})$ is the adsorbed amount, and $\Delta S_{n}$ is the entropy of adsorption.

The values of the isosteric heats of adsorption for the three kinds of VOCs together with the amount adsorbed are depicted in Fig. 2. It can be observed that the isosteric heat of adsorption for cyclohexane and hexane gradually decrease as the amount adsorbed increases, suggesting that the properties of synthesized OMC are heterogeneous (Dou et al., 2011). The adsorption of benzene seems different from the other two adsorbates in that the isosteric heats of adsorption gently increase as the amount adsorbed increases. This may be related to the higher $\pi-\pi$ interaction between benzene molecules after multi-layer adsorption (Bell et al., 2011). As the adsorbed amounts increase, planar aromatic adsorbate

Table 3 - Virial parameters for volatile organic compound (VOC) adsorption on OMC at $298 \mathrm{~K}, 308 \mathrm{~K}, 318 \mathrm{~K}$.

\begin{tabular}{|c|c|c|c|c|c|}
\hline Adsorbate & $\begin{array}{c}\text { Temperature } \\
(\mathrm{K})\end{array}$ & $\begin{array}{c}\mathrm{A}_{0} \\
(\ln (\mathrm{mol} / \mathrm{g} / \mathrm{Pa}))\end{array}$ & $\begin{array}{c}A_{1} \\
(\ln (\mathrm{g} / \mathrm{mol}))\end{array}$ & $\begin{array}{c}K_{0} \\
\left(\times 10^{-6}\right)\end{array}$ & $\mathrm{R}^{2}$ \\
\hline \multirow[t]{3}{*}{ Benzene } & 298 & -11.210 & -146.711 & 13.533 & 0.995 \\
\hline & 308 & -11.516 & -177.493 & 9.972 & 0.983 \\
\hline & 318 & -11.813 & -204.105 & 7.408 & 0.983 \\
\hline \multirow[t]{3}{*}{ Cyclohexane } & 298 & -10.554 & -271.491 & 26.099 & 0.996 \\
\hline & 308 & -10.934 & -304.584 & 17.836 & 0.986 \\
\hline & 318 & -11.649 & -320.074 & 8.731 & 0.998 \\
\hline \multirow[t]{3}{*}{ Hexane } & 298 & -10.678 & -385.938 & 23.040 & 0.999 \\
\hline & 308 & -10.803 & -429.705 & 20.334 & 0.999 \\
\hline & 318 & -11.385 & -413.608 & 11.361 & 0.999 \\
\hline
\end{tabular}


molecules such as benzene are prone to stack with each other and structural rearrangement occurs, giving higher intermolecular $\pi-\pi$ interaction.

\subsection{Adsorption kinetics}

Adsorption kinetics are of fundamental importance to reveal the transport process of adsorbates into adsorbents. In our study, the mass relaxation data recorded by IGA can be used to calculate the adsorption kinetics parameters. Several models such as linear driving force (LDF), double exponential and Fickian diffusion model have been used to describe the adsorption kinetics of gas adsorbates onto adsorbents (Bell et al., 2011). Previous studies have proved that the LDF model was followed for the adsorption of several kinds of gases/ vapors on carbon adsorbents such as activated carbon and carbon molecular sieves (Fletcher et al., 2006; Reid and Thomas, 2001). In addition, the LDF model involves a simpler
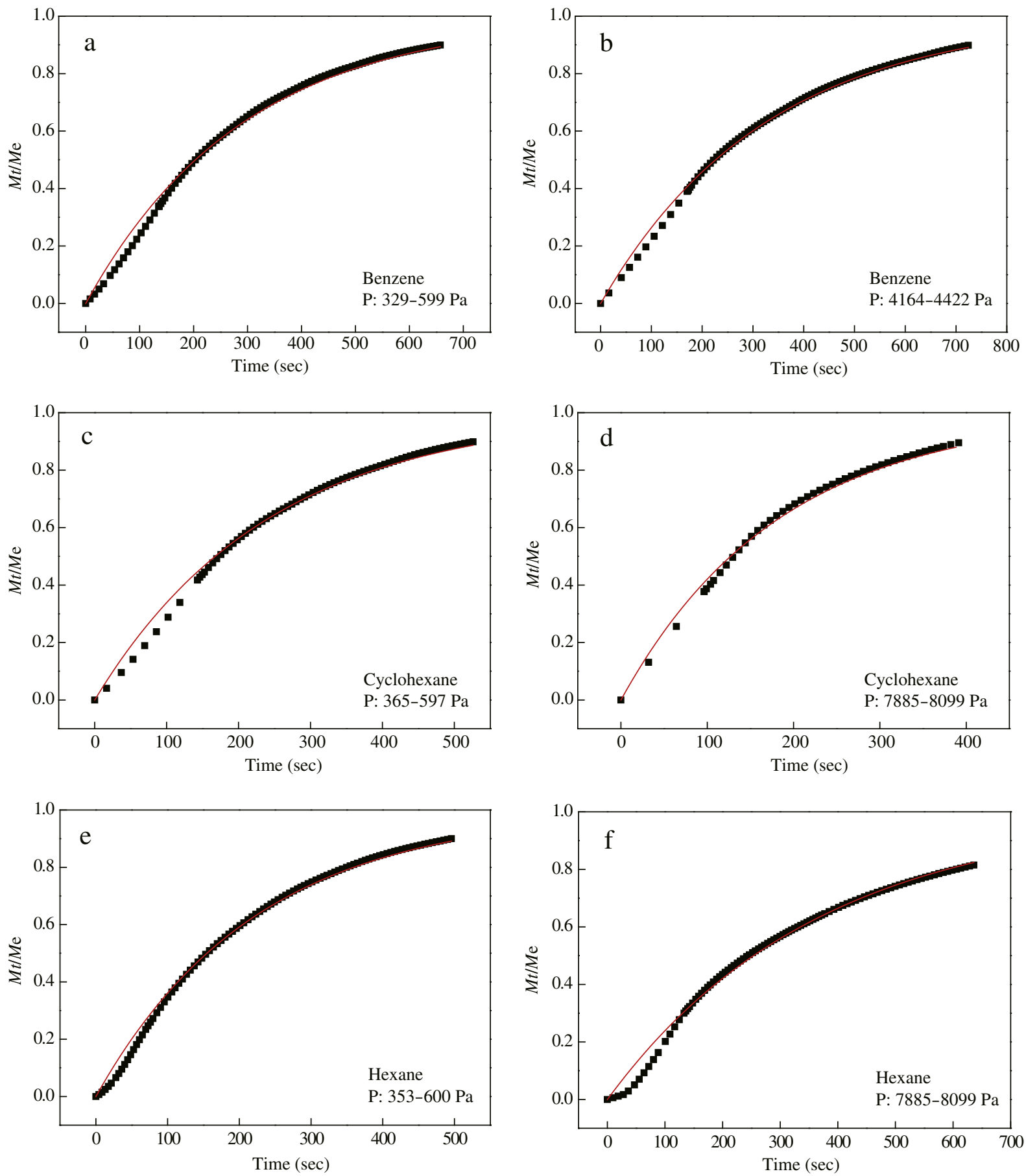

Fig. 3 - Adsorption kinetic profiles of benzene, cyclohexane, and hexane at $298 \mathrm{~K}$ on OMC, line is the linear driving force (LDF) model (every 20th points). 

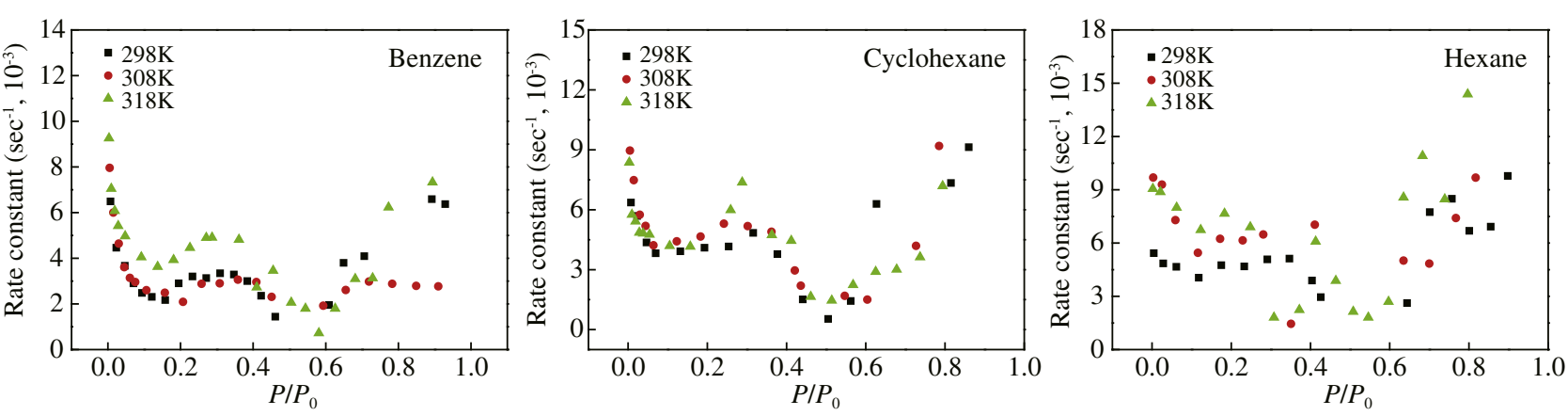

Fig. 4 - Kinetic rate constants of benzene, cyclohexane and hexane for adsorption on OMC with relative pressures under $298 \mathrm{~K}$, $308 \mathrm{~K}$, and $318 \mathrm{~K}$.

expression compared with other models and can be described by the following equation,

$M_{t} / M_{\mathrm{e}}=1-e^{-k t}$

where, $M_{t}$ is the adsorbed amount at time $t ; M_{e}$ is the equilibrium adsorbed amount for the given pressure increment, and $k$ is the rate constant.

Typical adsorption kinetics data and the corresponding simulative LDF curves for benzene ( $\mathrm{P}$ : 329-599 Pa, 4164-4422 Pa), cyclohexane (P: 365-597 Pa, 7885-8099 Pa) and hexane (P: 353-600 Pa, 8499-8950 Pa) at $298 \mathrm{~K}$ are depicted in Fig. 3. All graphs show that the adsorption kinetics obeys the LDF model with a good level of correlation. The slight deviation in the initial part of the simulated curves derives from the rapid changing of the vapor pressure in the instrument (Reid and Thomas, 2001). Further analysis verified that the adsorption kinetics of the three kinds of adsorbates at the experimental temperatures all follow the LDF model over most ranges of pressure.

The kinetic rate constants for the three kinds of adsorbates for each pressure step in the adsorption temperature range 298-318 K are shown in Fig. 4. For benzene adsorption at the selected temperature, the initial rate constant value at the lower relative pressure reaches about $9 \times 10^{-3}$, then a gradual decrease occurs with increasing relative pressure. The lowest rate constant appears when the relative pressures are between 0.4 and 0.6 , in accordance with the value where capillary condensation occurs. This suggests a slower adsorption rate for the condensation step than the initial adsorption stage, which is similar to the adsorption rate of water vapor on carbon molecular sieves (O'koye et al., 1997). After the pore condensation process was completed, the rate constants increased to about $8 \times 10^{-3}$, which may be caused by the rearrangement of adsorbed benzene molecules, allowing increased accessibility into the pore structure (Foley et al., 1997). As can be seen in the figure, the change of adsorption rate constants for cyclohexane and hexane is similar to that for benzene, and the corresponding rate constants for cyclohexane and hexane in the initial relative pressure ranges are also about $9 \times 10^{-3}$. This indicates that the pore size of OMC is large enough and thus favorable for the diffusion of adsorbates with different molecular sizes. In contrast, as the pore size of a microporous adsorbent becomes narrower, adsorbates with larger sizes would cause a decrease in the diffusion rate (Bell et al., 2011). Besides, it is notable that the kinetic rate constants at $318 \mathrm{~K}$ are larger than the corresponding values at 308 and $298 \mathrm{~K}$ for the three kinds of adsorbates, especially for benzene. This is reasonable if we consider the fact that a higher temperature will accelerate the diffusion of gas molecules. The diffusion properties of VOCs on other adsorbents such as activated carbon and carbon molecular sieves have been studied previously (Fletcher et al., 2006; Reid and Thomas, 2001). The corresponding results indicated that the diffusion rate constants of VOCs on activated carbon are mainly in the range of $(2-4) \times 10^{-3}$, which is almost half of the corresponding value for OMC. This suggests a relatively slower diffusion process for benzene in activated carbon than in OMC, as OMC possesses a larger pore size together with an ordered mesoporous structure.

It is generally accepted that the adsorption process of VOCs onto adsorbents can be described by the following steps: (1) mass transfer of adsorbates from the adsorbate phase to the surface of adsorbents, (2) diffusion of the adsorbate molecules into the pore channels of adsorbents, and (3) adsorption of adsorbates onto adsorbents (Wang et al., 2011). During our study, pure vapor of three kinds of adsorbates was generated and pumped to the adsorption chamber in which the adsorbents were located in a very short time, hence the mass transfer time of adsorbates can be neglected. Besides, the adsorption of adsorbates onto adsorbents is rapid compared with the other processes. Thus it is reasonable to assume that the adsorption process is controlled by the diffusion of adsorbate molecules into the pore channels of adsorbents. Previous studies pointed out that two kinds of barriers exist during the diffusion process: diffusion through the barrier at the pore entrance and diffusion along the pores (Fletcher et al., 2006; Reid and Thomas, 2001). The barrier around the pore entrance originates from the presence of discrete adsorption sites on the carbon basal plane of the outside surface. The adsorbate molecules must overcome the energy barrier to pass through the pore entrance and move into the inner part of the adsorbents. An LDF model is followed when the former barrier resistance is higher than the latter, i.e., the former process is the rate-determining step. In our research, the synthesized OMC has a bimodal-like pore size distribution with the pore sizes of 5.0 and $1.8 \mathrm{~nm}$, respectively. Both sizes are much smaller than the molecular mean free path of the three kinds of organic vapors, which is important in evaluating diffusion properties, with a value usually more than $100 \mathrm{~nm}$ (Fletcher et al., 2006). Thus it is relatively difficult for the vapor 
phase molecules to enter the pore channels of OMC. Furthermore, according to the principles of adsorption theory, a Knudsen diffusion process occurs when the mean free path of vapors is greater than the pore diameter and collisions between molecules of vapors are less frequent than collisions between vapor molecules and pore walls (Ruthven, 1984). Thus a general diffusion process of organic vapors onto OMC can be imagined such that the adsorption barrier originates from the difficulty VOC vapor molecules have in entering the pore channels of adsorbents and the following Knudsen diffusion, of which the former is the rate-determining step.

\section{Conclusions}

In this study, an OMC was synthesized via an EISA method and the resultant OMC has a large BET specific surface area and pore volume. Benzene, cyclohexane and hexane were selected as typical VOCs to evaluate the potential application of OMC as a VOCs adsorbent. The pore size of OMC is larger than and fully accessible to the adsorbates, thus the total pore volume can be used completely, and high adsorption amounts were achieved for all three VOCs in spite of their molecular size differences. Besides, the ordered mesoporous structure and the unusual bimodal-like pore size distribution, with the most probable pore sizes being 5.0 and $1.8 \mathrm{~nm}$, enables the adsorbates to have a higher Knudsen diffusion rate in OMC compared with conventional adsorbents such as activated carbon and carbon molecular sieve. Therefore, the OMC might have great potential application in the VOC adsorption and recovery regime due to its superior adsorption capacity and faster diffusion process than microporous adsorbents.

\section{Acknowledgments}

We gratefully acknowledge the financial support from the State Key program of National Natural Science Foundation (No. 21337003), the Strategic Priority Research Program (No. XDB05050200), the National High Technology Research and Development Program of China (2012AA063101), the Special Environmental Protection Foundation for Public Welfare Project (No. 201309073), and the Team Interaction and Cooperation of the Science and Technology Program of the Chinese Academy of Sciences.

\section{Appendix A. Supplementary data}

Supplementary data to this article can be found online at http:// dx.doi.org/10.1016/j.jes.2014.10.015.

\section{R E F E R E N C E S}

Bell, J.G., Zhao, X., Uygur, Y., Thomas, K.M., 2011. Adsorption of chloroaromatic models for dioxins on porous carbons: the influence of adsorbate structure and surface functional groups on surface interactions and adsorption kinetics. J. Phys. Chem. C 115 (6), 2776-2789.
Britt, D., Tranchemontagne, D., Yaghi, O.M., 2008. Metal-organic frameworks with high capacity and selectivity for harmful gases. Proc. Natl. Acad. Sci. U. S. A. 105 (33), 11623-11627.

de Souza, S.M.D.G.U., da Luz, A.D., da Silva, A., de Souza, A.A.U., 2012. Removal of mono- and multicomponent BTX compounds from effluents using activated carbon from coconut shell as the adsorbent. Ind. Eng. Chem. Res. 51 (18), 6461-6469.

Dou, B., Li, J., Wang, Y., Wang, H., Ma, C., Hao, Z., 2011. Adsorption and desorption performance of benzene over hierarchically structured carbon-silica aerogel composites. J. Hazard. Mater. 196, 194-200.

Fletcher, A.J., Yüzak, Y., Thomas, K.M., 2006. Adsorption and desorption kinetics for hydrophilic and hydrophobic vapors on activated carbon. Carbon 44 (5), 989-1004.

Foley, N.J., Thomas, K.M., Forshaw, P.L., Stanton, D., Norman, P.R., 1997. Kinetics of water vapor adsorption on activated carbon. Langmuir 13 (7), 2083-2089.

Gao, W.J., Wan, Y., Dou, Y.Q., Zhao, D.Y., 2011. Synthesis of partially graphitic ordered mesoporous carbons with high surface areas. Adv. Energy Mater. 1 (1), 115-123.

Ghoshal, A.K., Manjare, S.D., 2002. Selection of appropriate adsorption technique for recovery of VOCs: an analysis. J. Loss Prev. Process Ind. 15 (6), 413-421.

Gonzalez-Miquel, M., Palomar, J., Rodriguez, F., 2013. Selection of ionic liquids for enhancing the gas solubility of volatile organic compounds. J. Phys. Chem. B 117 (1), 296-306.

Hartmann, M., Vinu, A., Chandrasekar, G., 2005. Adsorption of vitamin $\mathrm{E}$ on mesoporous carbon molecular sieves. Chem. Mater. 17 (4), 829-833.

He, C., Xu, L.L., Yue, L., Chen, Y.T., Chen, J.S., Hao, Z.P., 2012. Supported nanometric pd hierarchical catalysts for efficient toluene removal: catalyst characterization and activity elucidation. Ind. Eng. Chem. Res. 51 (21), 7211-7222.

Hernandez, M.A., Velasco, J.A., Asomoza, M., Solis, S., Rojas, F., Lara, V.H., et al., 2003. Alkane adsorption on microporous $\mathrm{SiO}_{2}$ substrata. 1. Textural characterization and equilibrium. Energy Fuel 17 (2), 262-270.

Jhung, S.H., Lee, J.H., Yoon, J.W., Serre, C., Ferey, G., Chang, J.S., 2007. Microwave synthesis of chromium terephthalate MIL-101 and its benzene sorption ability. Adv. Mater. 19 (1), 121-124.

Ji, L.L., Liu, F.L., Xu, Z.Y., Zheng, S.R., Zhu, D.Q., 2010. Adsorption of pharmaceutical antibiotics on template-synthesized ordered micro- and mesoporous carbons. Environ. Sci. Technol. 44 (8), 3116-3122.

Li, W., Zhao, D.Y., 2013. An overview of the synthesis of ordered mesoporous materials. Chem. Commun. 49 (10), 943-946.

Li, J.R., Kuppler, R.J., Zhou, H.C., 2009. Selective gas adsorption and separation in metal-organic frameworks. Chem. Soc. Rev. 38 (5), 1477-1504

Lillo-Rodenas, M.A., Fletcher, A.J., Thomas, K.M., Cazorla-Amoros, D., Linares-Solano, A., 2006. Competitive adsorption of a benzene-toluene mixture on activated carbons at low concentration. Carbon 44 (8), 1455-1463.

Lin, H.W., Jang, M., Suslick, K.S., 2011. Preoxidation for colorimetric sensor array detection of VOCs. J. Am. Chem. Soc. 133 (42), 16786-16789.

Ma, T.Y., Liu, L., Yuan, Z.Y., 2013. Direct synthesis of ordered mesoporous carbons. Chem. Soc. Rev. 42 (9), 3977-4003.

Nevskaia, D.M., Castillejos-Lopez, E., Munoz, V., Guerrero-Ruiz, A., 2004. Adsorption of aromatic compounds from water by treated carbon materials. Environ. Sci. Technol. 38 (21), 5786-5796.

O'koye, I.P., Benham, M., Thomas, K.M., 1997. Adsorption of gases and vapors on carbon molecular sieves. Langmuir 13 (15), 4054-4059.

Parmar, G.R., Rao, N.N., 2009. Emerging control technologies for volatile organic compounds. Crit. Rev. Environ. Sci. Technol. 39 (1), 41-78.

Ramirez, D., Qi, S.Y., Rood, M.J., 2005. Equilibrium and heat of adsorption for organic vapors and activated carbons. Environ. Sci. Technol. 39 (15), 5864-5871. 
Reguer, A., Sochard, S., Hort, C., Platel, V., 2011. Measurement and modelling of adsorption equilibrium, adsorption kinetics and breakthrough curve of toluene at very low concentrations on to activated carbon. Environ. Technol. 32 (7), 757-766.

Reid, C.R., Thomas, K.M., 2001. Adsorption kinetics and size exclusion properties of probe molecules for the selective porosity in a carbon molecular sieve used for air separation. J. Phys. Chem. B 105 (43), 10619-10629.

Ruthven, D.M., 1984. Principles of Adsorption and Adsorption Processes. John Wiley-Interscience, New York, USA.

Sing, K.S.W., 1985. Reporting physisorption data for gas/solid systems with special reference to the determination of surface area and porosity (Recommendations 1984). Pure Appl. Chem. 57 (4), 603-619.

Speight, J.G., 2005. Lange's Handbook of Chemistry. 6th ed. McGraw-Hill, New York, USA.

Tanaka, S., Doi, A., Matsui, T., Miyake, Y., 2013. Mass transport and electrolyte accessibility through hexagonally ordered channels of self-assembled mesoporous carbons. J. Power Sources 228, 24-31.

Wang, S., Ang, H.M., Tade, M.O., 2007. Volatile organic compounds in indoor environment and photocatalytic oxidation: state of the art. Environ. Int. 33, 694-705.

Wang, D., McLaughlin, E., Pfeffer, R., Lin, Y.S., 2011. Adsorption of organic compounds in vapor, liquid, and aqueous solution phases on hydrophobic aerogels. Ind. Eng. Chem. Res. 50 (21), 12177-12185.
Wang, H., Jahandar Lashaki, M., Fayaz, M., Hashisho, Z., Philips, J.H., Anderson, J.E., et al., 2012. Adsorption and desorption of mixtures of organic vapors on beaded activated carbon. Environ. Sci. Technol. 46 (15), 8341-8350.

Wang, S., Zhao, Q., Wei, H., Wang, J.Q., Cho, M., Cho, H.S., et al., 2013. Aggregation-free gold nanoparticles in ordered mesoporous carbons: toward highly active and stable heterogeneous catalysts. J. Am. Chem. Soc. 135 (32), 11849-11860.

Webster, C.E., Drago, R.S., Zerner, M.C., 1998. Molecular dimensions for adsorptives. J. Am. Chem. Soc. 120 (22), 5509-5516.

Wu, Y., Wang, R.J., Zhou, Y., Lin, B.H., Fu, L.X., He, K.B., et al., 2011. On-road vehicle emission control in Beijing: past, present, and future. Environ. Sci. Technol. 45 (1), 147-153.

Yang, K., Sun, Q., Xue, F., Lin, D.H., 2011. Adsorption of volatile organic compounds by metal-organic frameworks MIL-101: influence of molecular size and shape. J. Hazard. Mater. 195, 124-131.

Yu, M., Hunter, J.T., Falconer, J.L., Noble, R.D., 2006. Adsorption of benzene mixtures on silicalite-1 and NaX zeolites. Microporous Mesoporous Mater. 96 (1-3), 376-385.

Yuan, B., Wu, X.F., Chen, Y.X., Huang, J.H., Luo, H.M., Deng, S.G., 2013. Adsorption of $\mathrm{CO}_{2}, \mathrm{CH}_{4}$, and $\mathrm{N}_{2}$ on ordered mesoporous carbon: approach for greenhouse gases capture and biogas upgrading. Environ. Sci. Technol. 47 (10), 5474-5480.

Zhuang, X., Wan, Y., Feng, C.M., Shen, Y., Zhao, D.Y., 2009. Highly efficient adsorption of bulky dye molecules in wastewater on ordered mesoporous carbons. Chem. Mater. 21 (4), 706-716. 